\section{Beginning Landscape Design: Framework and Fundamentals}

\author{
Pauline Hurley-Kurtz
}

AdDITIONAL INDEX WORDS. design principles, spatial hierarchy, design process

SummaRY. There are growing employment opportunities in the burgeoning landscape industry for well trained, ecologically sensitive landscape designers. This paper describes an approach to beginning design for horticulture and landscape architecture students at Temple University's Ambler, Pa., campus, where the emphasis is on teaching design process and principles within an ecological framework. Preliminary exercises focus on an examination of landscape values, the application of design principles and the study of design precedent. Students then apply principles learned within an ecological design process as they design a campus garden or public space.

S trong design skills are excellent tools for horticulture graduates who wish to find employment in the landscape industry. The American Nursery and Landscape Association (2000) states that the landscape design, installation, maintenance and retail industry in the United States was valued at $\$ 46.9$ billion in 1998 . Nursery and greenhouse crops are now the second most important sector in United States agriculture growing at a

Associate professor, Department of Landscape Architecture and Horticulture, Temple University, 580 Meetinghouse Rd., Ambler, PA 19006-3994.

Since 1996, a number of instructors have greatly contributed to the development of the beginning design sequence in the horticulture and landscape architecture curricula, and deserve recognition. They are E. Anderson, M. Bowe, D. Kessler and J. Meschter. Work illustrated in this paper was generated in the basic design seminar and studios taught by E. Anderson, M Bowe, C. Krawczyck and the author. Also, thanks to L. Blum, G. Whiting, and B. Lamba, for reviewing this paper in it's early stages. Special thanks to R. Lyons for his thorough editing and patience. The cost of publishing this paper was defrayed in part by the payment of page charges. Under postal regulations, this paper therefore must be hereby marked advertisement solely to indicate this fact. rate of about $\$ 500$ million peryear. This indicates an increasing interest in horticulture and gardening. Demographics point to a continuation of this trend as baby boomers reach middle age. Hence there will be an increasing market for well-trained landscape designers and plant professionals.

A fundamental strength of Temple University's horticulture and landscape architecture programs is a commitment to a shared curriculum in science, horticulture, graphics and design. Our landscape architecture graduates are trained plantsmen, and our horticulture graduates receiveinstructionindesign. Studentsfrom both programs work together in studio, plant science and landscape restoration courses. Thispaperdescribesan overarching approach to beginning landscape designin the Department of Landscape Architecture and Horticulture, Temple University, Ambler, Pa.

\section{Beginning landscape design}

There are two studios in the horticulture curriculum that address graphics and beginning design respectively. Studios occur in the second year of the horticulture program and typically have 12-15 students. The graphic communication seminar (LAl01) and studio (LA 103) sequence is their first studio experience and is taken jointly by horticulture and landscape architecture students. Subsequently, the beginning landscape design studios (LA 102, LA 104, Hort 52) are taken independently.

The content and format of these parallel studios is related due to the core faculty that teach beginning design in both programs. Within the given structure, individual faculty may reinterpret and modify their particular studio in a given semester. This ultimately enhances the pedagogical experience.

Four plant materials courses augment the design skills horticulture students learn in studios: Woody Plants I and II(Hort 107, 108) and Herbaceous Plants I and II (Hort 201, 202). Herbaceous Plants I (annuals) and II (perennials) also have design components. Three of these courses are taken jointly by horticulture and landscape architecture students.

\section{The beginning landscape design sequence}

Place, memory, meaning. The beginning design studio commences with an exercise that explores the students' 


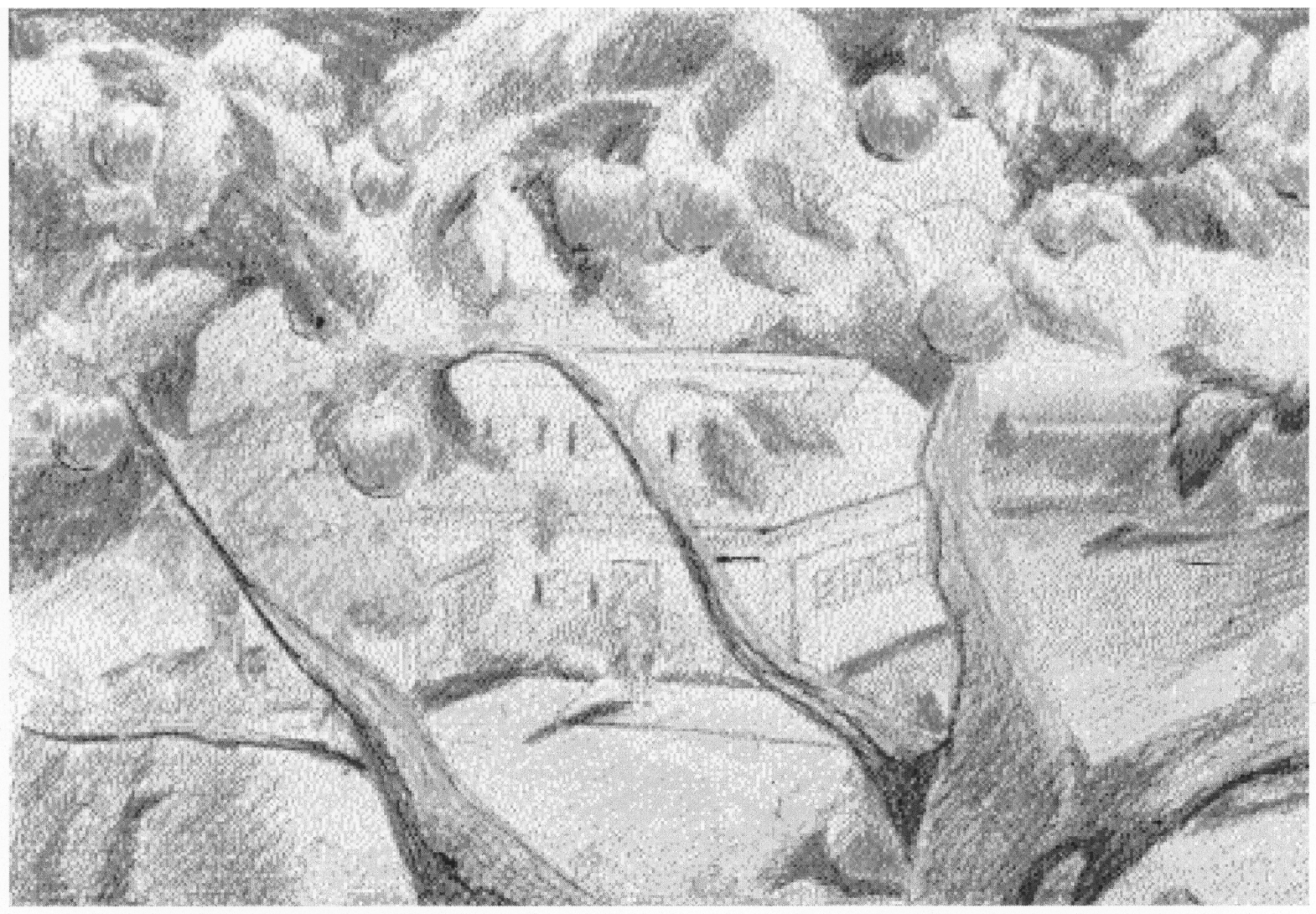

Fig.1A

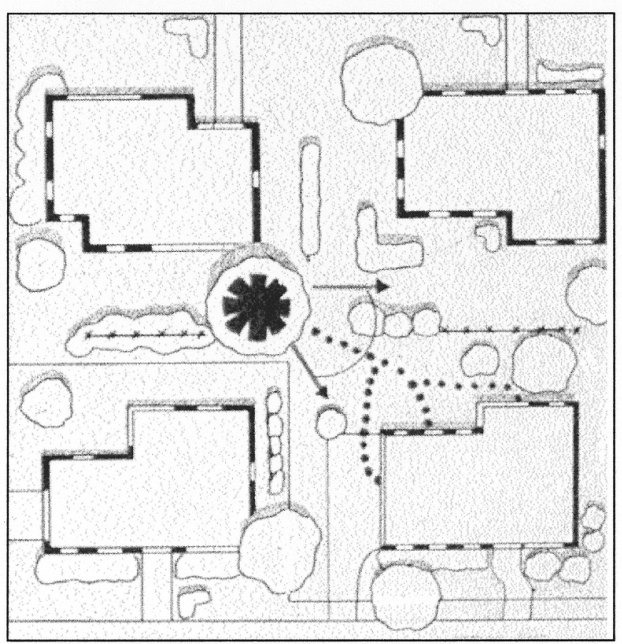

Fig.1B

Fig. 1 (A) Sketch describing a favorite childhood landscape (by J. Petrowsky in 1998). (B) Diagram of neighborhood features as part of the place, memory meaning childhood landscape study (by $\mathrm{J}$. Petrowsky in 1998).

design preferences and landscape values. Students remember a favorite childhood landscape, write about it, draw it and analyze its structure and context. Clare Cooper-Marcus (1978) states: "All of us carry the memory seeds of childhood landscapes those environments we encountered, smelled, dug in, climbed and explored, when our senses seemed most tantalizingly alive. The smell of a certain flower, the call of a favorite bird, the sight of a familiar staircase, or porch or attic window can trigger the floodgate of memories. We explore the place in our minds eye, almost feeling the texture of the tree trunk, almost smelling the musty odor of grandmother's basement." Students recall the sense of place of their childhood landscape through a variety of drawings (Fig. 1A). They are asked to describe the structure of this place in particular the nature of the ground, vertical and overhead planes; the quality of light and temperature; the sense of enclosure and the type of views. They also analyze the character of the larger context and are introduced to the concept of imageability analysis. Lynch (1979) describes imageability as "that quality in a physical object which gives it a high probability of evoking a strong image in any given observer. It is that shape, color, or arrangement which facilitates the making of vividly identified, powerfully structured, highly use- ful mental images of the environment." Lynch suggests a number of criteria to be included in defining a landscape's imageability. These are paths, edges, nodes, districts and landmarks, and students apply the appropriate criteria to the analysis of the context of their site (Fig. 1B). This exercise examines how landscape memory can influence one's values and preferences as a designer. It also requires students to use a number of illustrative and analysis drawing techniques learned in the previous graphic communication studio thus reinforcing these skills.

\section{Design in two dimensions}

Classic design principles such as unity, balance, harmony, integration and simplicity are introduced in the second project of the semester. Students learn about design principles as they are expressed in art and in geometric design studies (Wong, 1988). They subsequently apply these design principles in a studio project using two dimensional geometric forms. This topic begins with a composition exercise that introduces the golden section proportional system. Motloch (1991) states: "The golden section also called the golden mean or the golden number, was believed by the early Greeks to be 
the perfect proportional relationship. They understood the golden section to play an important role in the proportion of the human body; and they proportioned their temples accordingly. The golden section states that the smaller part of a whole is to the larger part, as the larger part is to the sum of the two." This is represented by the equation $A: B$ $=\mathrm{B}(\mathrm{A}+\mathrm{B})$, and it conveys a pleasing relationship between design elements. It is evident in nature in the spiral of a seashell, and has been used through the ages as an ordering system in design as exemplified by Le Corbusier's Modu- lar.

Students choose one basic geometric shape, the form of which may later be applied to landscape design. From one 2 -inch $(5-\mathrm{cm})$ circle, students create a number of larger and smaller circles that are related by golden section proportions. From these, they develop a composition that expresses one of the design principles. Preliminary work is done on tracing paper. The final composition is painted on bristol board with gouache (Fig. 2A).

In the second study, students choose a 2-inch square from their com-

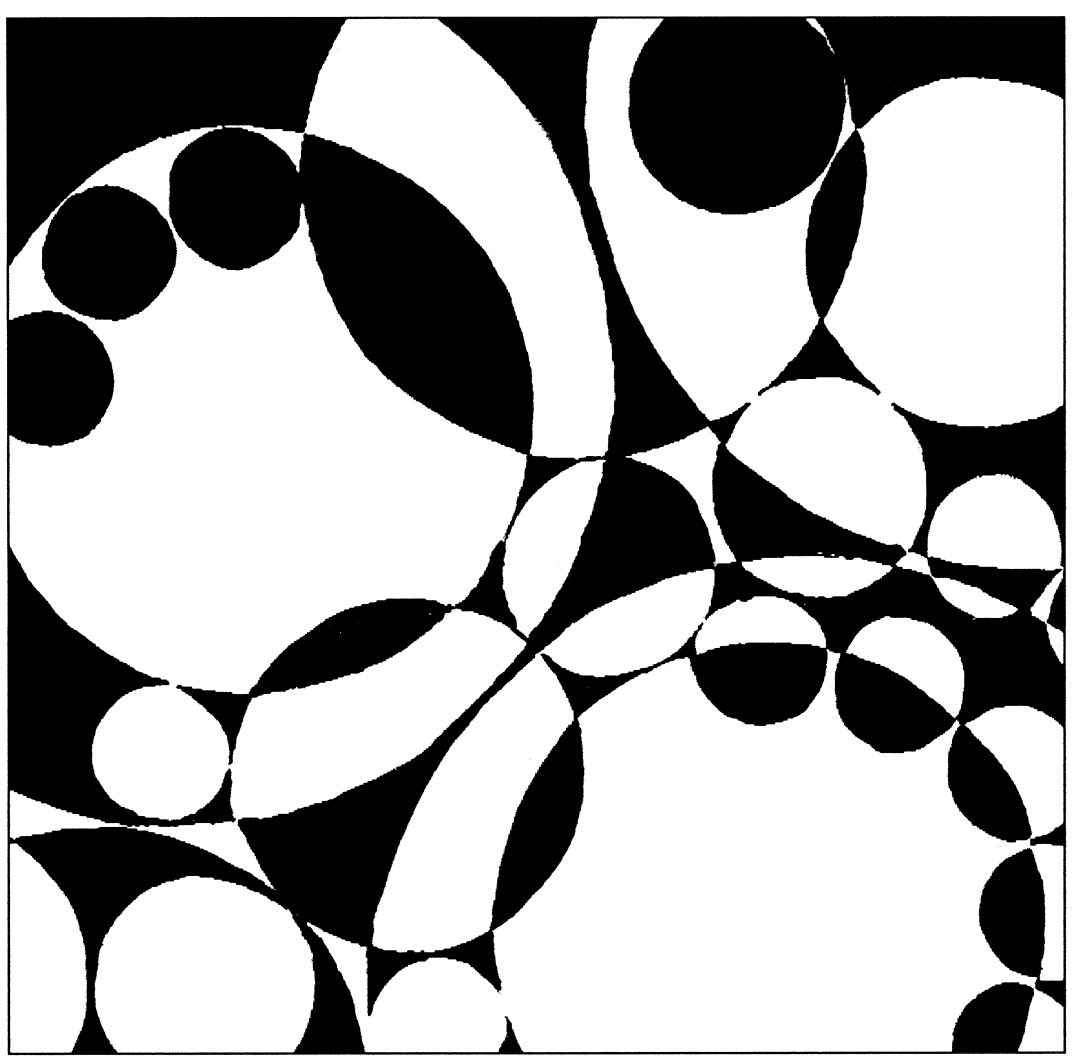

Fig.2A

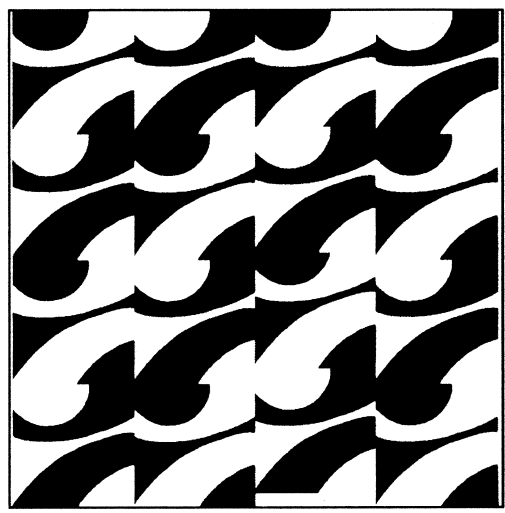

Fig.2C

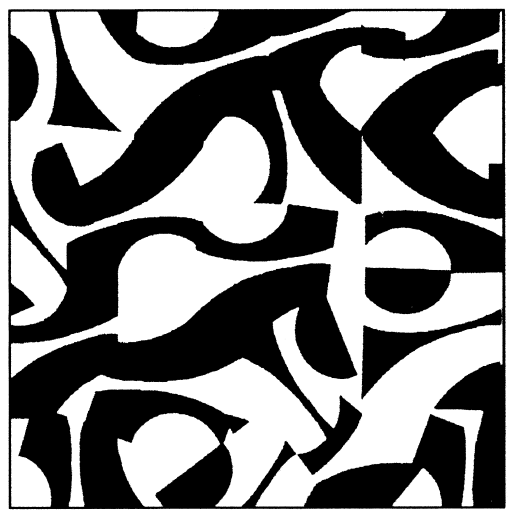

Fig.2D position board and use it as a building block for further design investigation. The building block should express the character of their chosen geometry, and should also be relatively balanced in black and white. These are scanned into Photoshop (Adobe Systems Inc., San Jose, Calif.) and are depicted in their positive and negative forms using the transparent and invert commands (Fig. $2 \mathrm{~B})$. This is a means of introducing the figure-ground concept often used in landscape typology studies and urban design analysis.

The third study investigates the application of grid as a form in nature, landscape, urban design and architecture. One may observe grid applied in a system of streets; in the planting of an orchard, bosque or allee; in the structure of a building. The goal in this study is to express the ideas of grid using the positive and negative figure-ground building blocks (Fig. 2C).

Fig. 2. (A) A two-dimensional composition expressing unity and asymmetrical design. (by S.W. Vandegrift in 1999). (B) Geometric building blocks in a twodimensional design study (by $S$.W. Vandegrift in 1999). (C) A two-dimensional design study expressing grid and architectonic form (by S.W. Vandegrift in 1999). (D) A two-dimensional design study expressing meander and naturalistic form (by S.W. Vandegrift in 1999). (E) A two-dimensional design study expressing the integration of architectonic and naturalistic form (by S.W. Vandegrift in 1999).

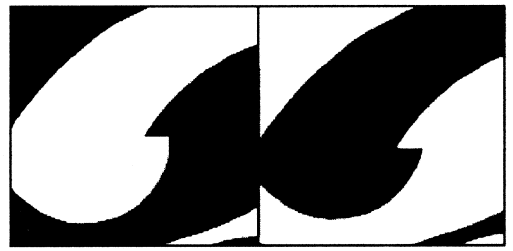

Fig.2B

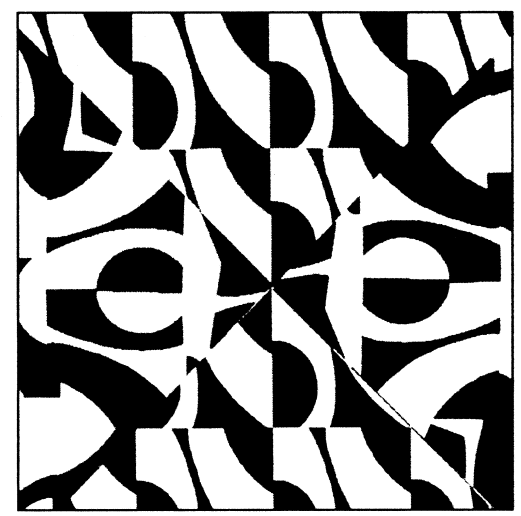

Fig.2E 
In contrast, students then express naturalistic or meandering forms with the same basic geometric building block thus developing familiarity with a natural landscape vocabulary (Fig. 2D). The final twodimensional study of this sequence is an integration of geometric and naturalistic forms, a theme which may be applied to transition areas between urban and natural zones (Fig. 2E).

Photoshop is used only as a design tool in this sequence. The invert, transform and rotate commands allow for rapid testing of the grid and meander concepts. Students work with multiple layers and the polygonal lasso tool to test a number of versions of the integration study. This is an introduction to the software for the majority of students, and it is fair to say that the instructor needs a firm grasp of the software to be successful in this exercise.

\section{Design in three dimensions}

The third studio exercise is a vigorous investigation of design principles in three dimensions using study models. It can be a continuation of the previous exercise given a third dimension. Emphasis is placed on the translation of abstract geometry and design principles to comfortable spaces that work with the ecology of a site. The first study model explores creating spaces, paths and focal points by manipulating contours and creating land form (Fig. 3A).

These same principles of space, circulation and focal point are then explored using planting only. As we take an ecological approach to planting design, students are introduced to the concepts of plant association and succession as possible themes. They develop a conceptual planting plan based on ecological principles, develop a plant list and construct a model. The planting design may be naturalistic or may include a more formal expression of architecture and geometry in the landscape such as an allee or bosque (Fig. 3B).

The program for the final model in this series is the design of a landscape that includes a variety of landform, vegetation, water and structures. This imaginary landscape has a hierarchy of spaces, paths and vistas. The overall composition embodies one or more landscape design principles (Fig. 3C).

\section{Design investigation study}

The study of precedent in landscape design is the goal of the design investigation project. Students choose a
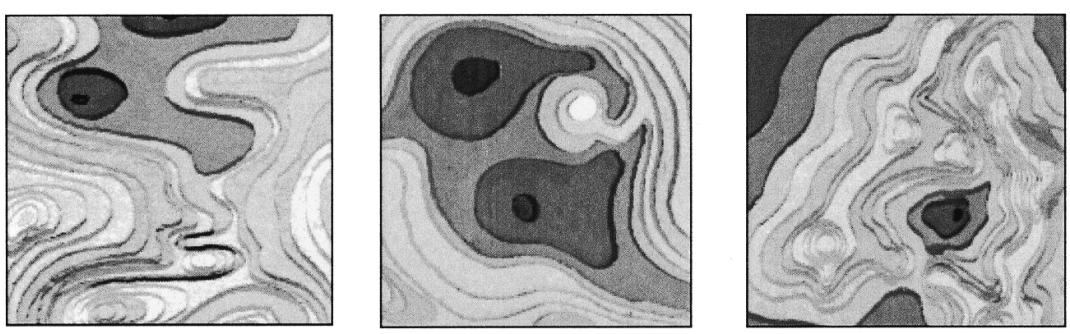

Fig.3A

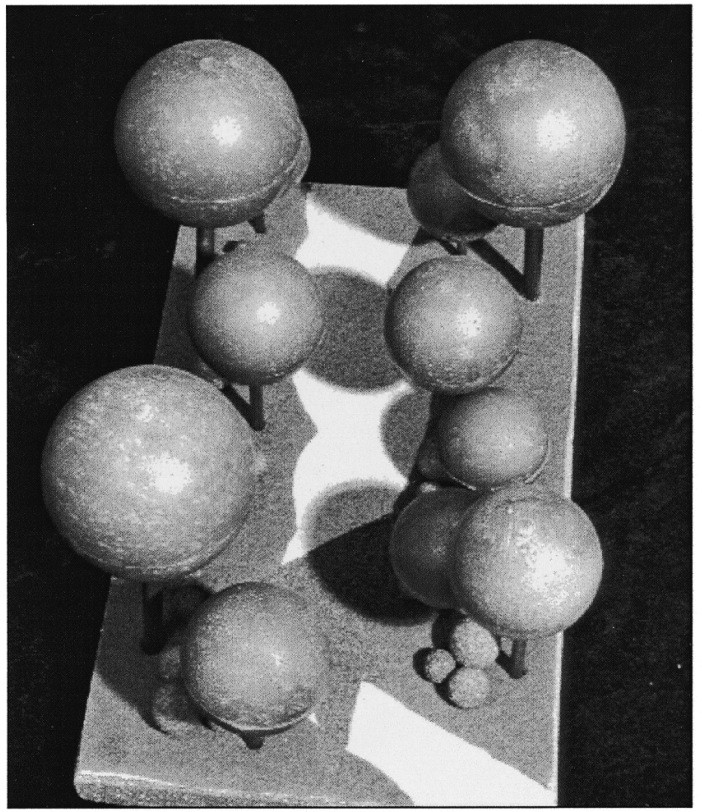

Fig. 3B

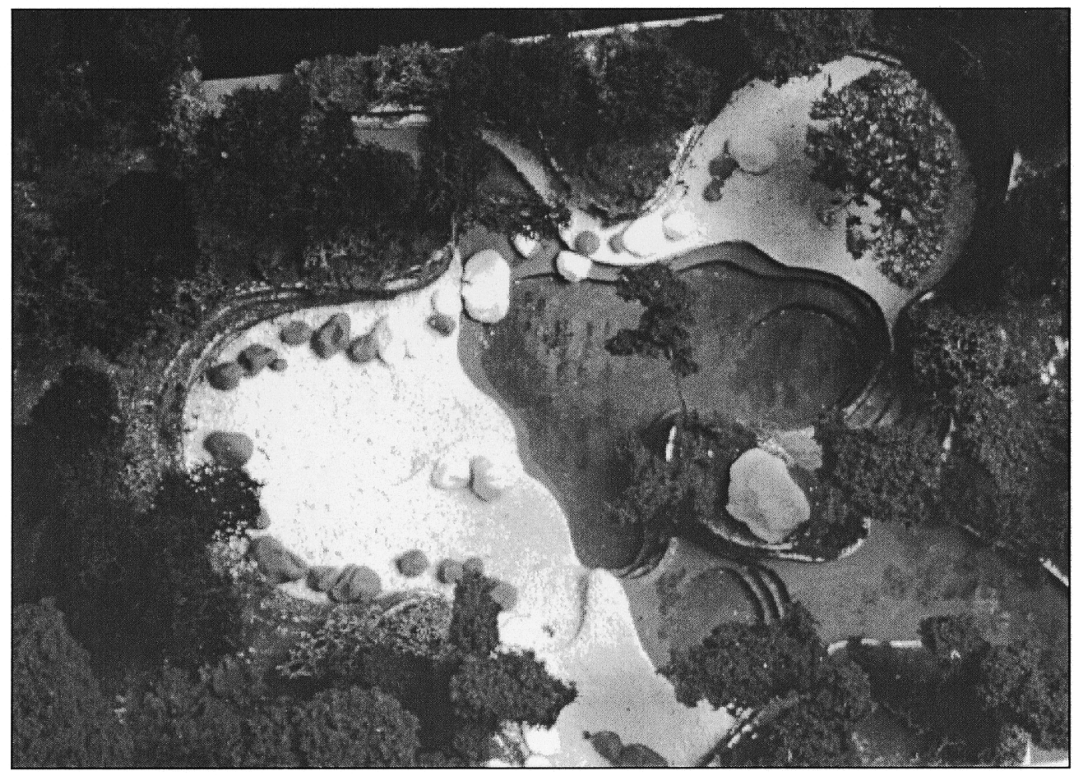

Fig. 3C

Fig. 3. (A) A three-dimensional topographic study defining space, path and focal point (by A. Bortnik in 1998). (B) A three-dimensional planting model that expresses space, path and focal point (by T.E. Peterson in 1999). (C) A three-dimensional design study that explores the integration of topography and planting in the creation of a hierarchy of spaces (by A. Bortnik in 1998). 

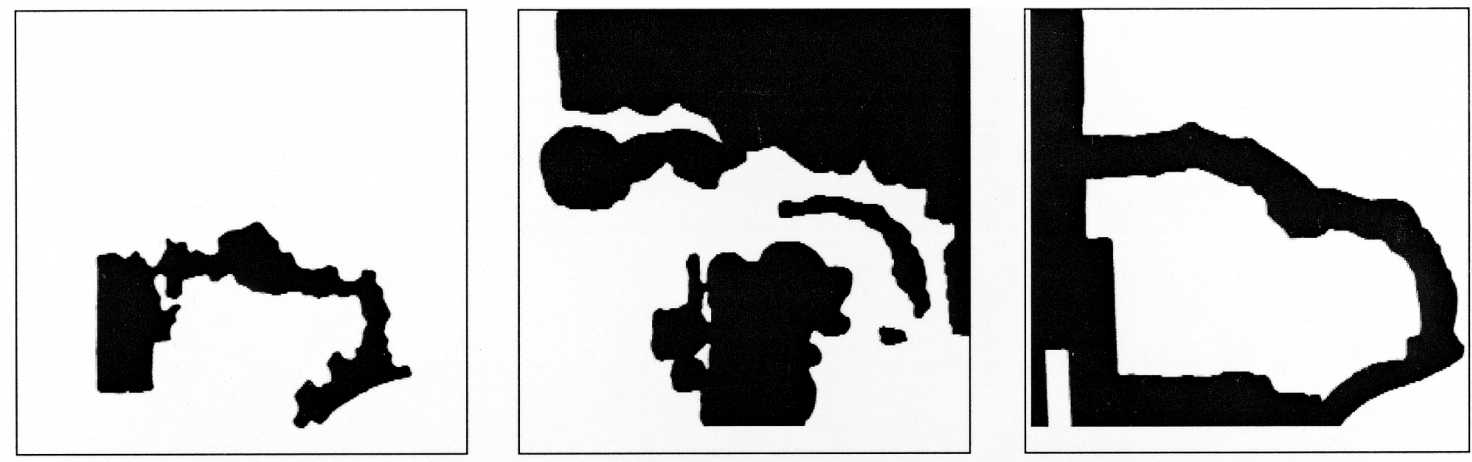

Fig.4A

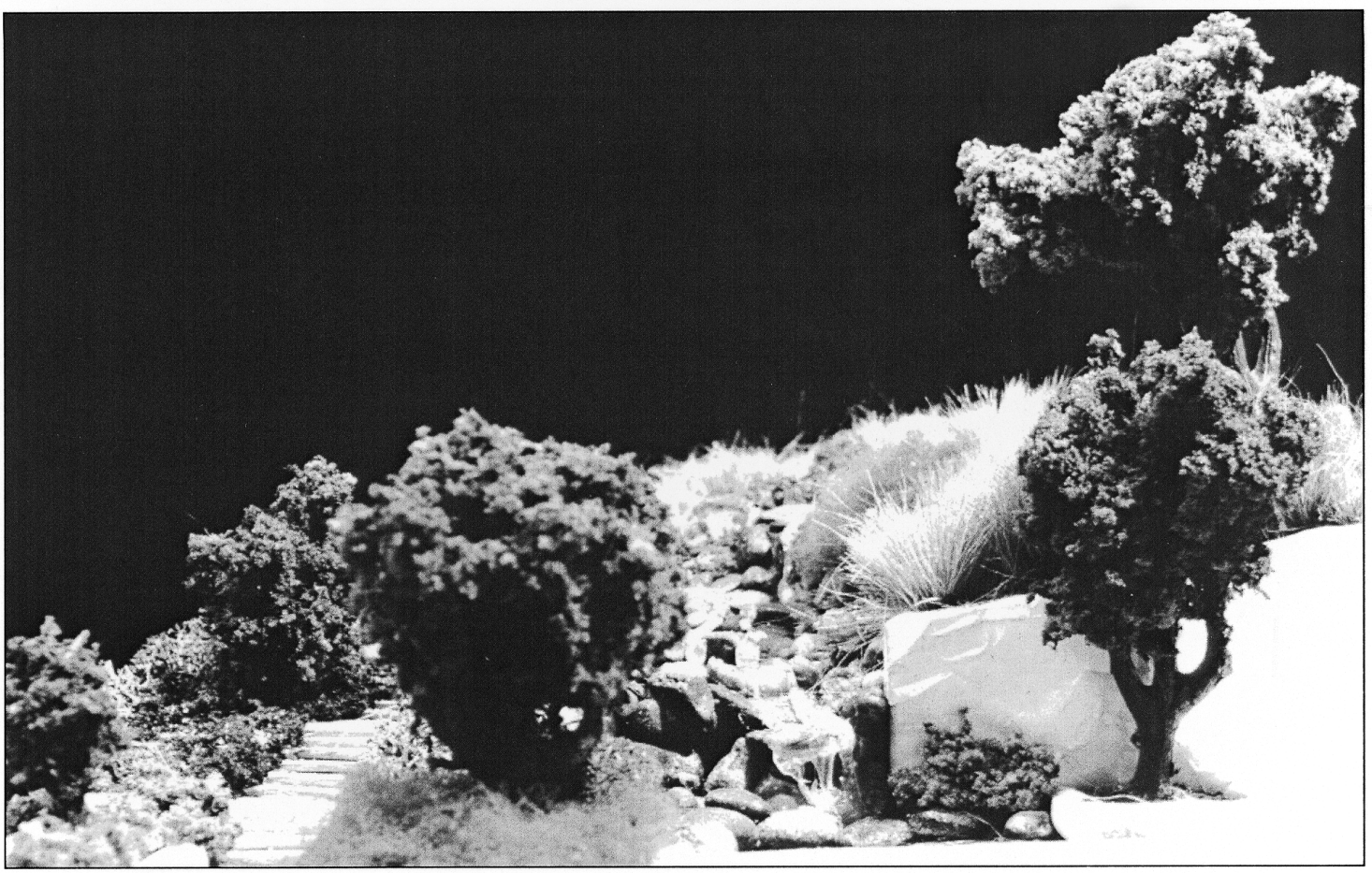

Fig.4B

Fig. 4. (A) Design investigation study of a residential garden near Winchester, Va., that was designed by Oehme, Van Sweden and Associates, Inc., Washington, D.C. These figure ground drawings describe water, space and circulation in the garden (by B.C. Whiting et al. in 1998). (B) Scale model developed as part of the design investigation study of a residential garden near Winchester, Va., that was designed by Oehme, Van Sweden and Associates, Inc., Washington, D.C. (by B.C. Whiting et al. in 1998).

favorite landscape, research and analyze the design and present their report to the class. The landscape may be one that clearly expresses cultural norms as in the Moorish gardens of Alhambra, Spain, or the Imperial landscapes of Kyoto, Japan. It may be a project of a favorite landscape designer, or a local garden that one can visit in the Delaware Valley near Ambler, Pa. The objective is to determine the overall principles expressed in the design. The final presentation requirements include: plan and section drawings; a series of typology studies of the landscape's constituent elements such as trees, water, circulation, space, steps and walls (Fig. 4A); a summary of the landscape's history and an account of the designers work. A scale model is also required (Fig. 4B).

The experience of precedent in landscape design is further enhanced by field trips in alternating years to New York and Washington, D.C. The itinerary varies from Central, Paley, and Bryant parks in New York to Dumbarton Oaks and memorials on the Mall in Washington, D.C.

\section{Landscape design project}

The final project of the semester is the application of landscape design principles and precedent learned in prior exercises to the design of a public or private garden. Many of the public gardens are designed for campus sites. Students are introduced to the components of the landscape design process that includes the following stages: site analysis; concept design; master plan; design development; construction documentation specification and construction administration. Emphasis is placed on the cyclical nature of the process and an ecological approach to design.

Students begin the process by con- 


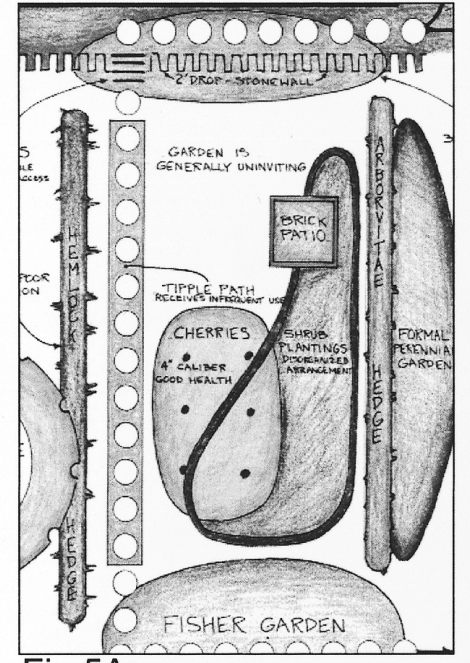

Fig.5A

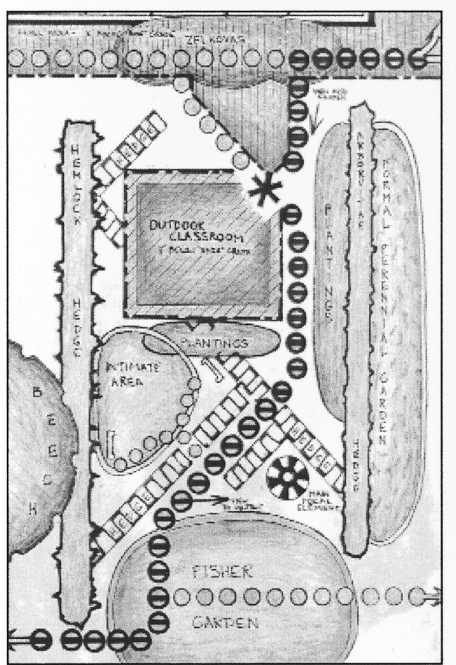

Fig.5B

Fig. 5. (A) Site analysis diagram describing existing conditions in a garden on the Ambler, Pa., campus of Temple University (by W.T.

Reichner in 1999). (B)

Concept design diagram summarizing a design proposal for a garden on the Ambler, Pa., campus of Temple University (by W.T. Reichner in 1999). (C) A master plan illustrating a design proposal for a garden on the Ambler, Pa., campus of Temple University (by W.T. Reichner in 1999). (D) A perspective sketch illustrating the character of the proposed garden on the Ambler, Pa., campus of Temple University (by W.T. Reichner in 1999).

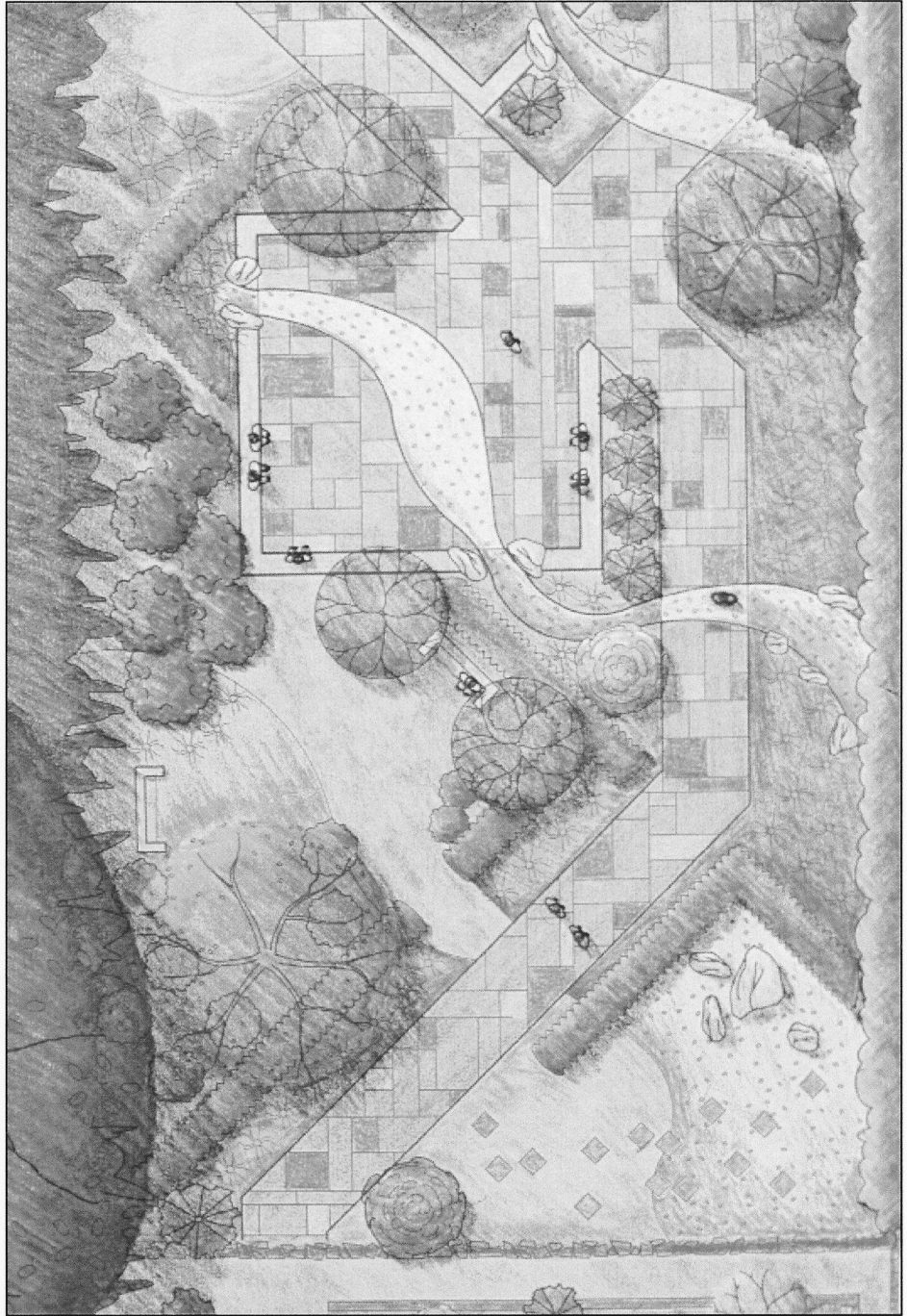

Fig.5C

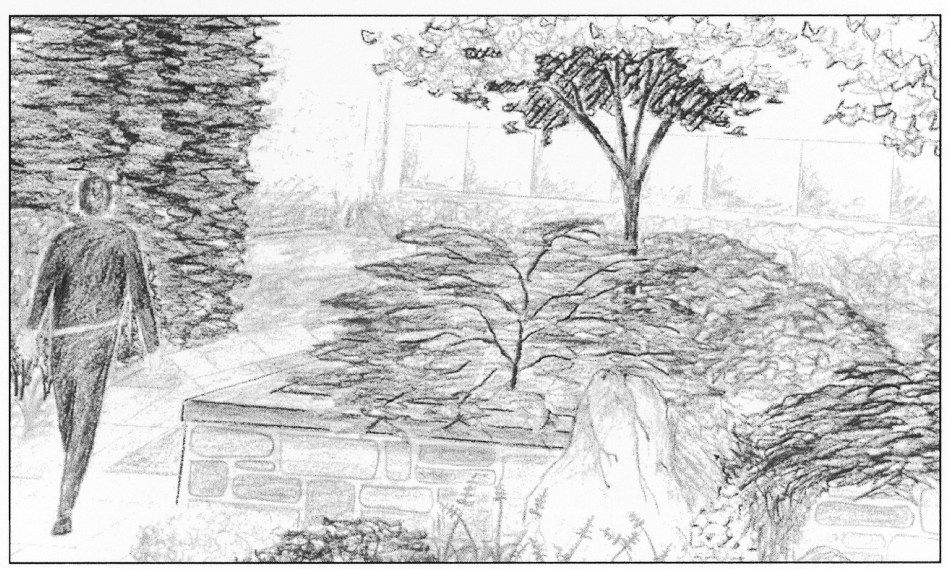

ducting a site analysis appropriate to the scale of their site in order to understand the opportunities and constraints for design (Fig. 5A). Site analysis components include soils, slope, aspect, vegetation, views and circulation. The process of ecological site analysis creates a framework for design. In the second stage of the design process, students test various design concepts for a particular program for the site (Fig. 5B). They are encouraged to show a strong response to the site analysis. This would translate to avoiding construction in wet soils, floodplains and on steep slopes while preserving existing vegetation, and optimizing views and solar aspect.

The design program generally includes a public gathering space, a quieter, more private sitting space and a water 


\section{Landscape Values Design Principles Design Precedent
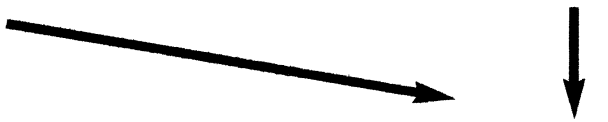 \\ Ecological Design Process \\ $\forall$ \\ Site Analysis \\ $\downarrow$ \\ Concept Design \\ $\checkmark$ \\ Master Plan

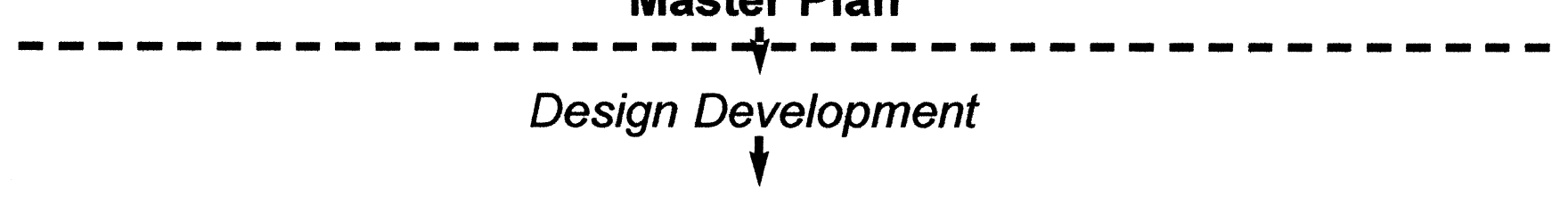 \\ Construction Documentation \\ $\downarrow$ \\ Construction Administration}

Fig. 6. A diagram illustrating the design process. Elements above the dashed line are included in beginning design studios in the Department of Landscape Architecture and Horticulture at Temple University (by M.P. Hurley-Kurtz in 2000).

element or sculpture. Consideration is given to a hierarchy of paths and views within and beyond the garden. The context of the garden is also included and students are encouraged to propose a design theme that will enhance the character of the arboretum at Ambler, Pa. The final drawing requirements include analysis and concept diagrams; a master plan (Fig. 5C), section and perspective views to illustrate the design (Fig 5D). A threedimensional model is also required to conclude the project.

\section{Discussion}

Students receive a thorough background in classical design principles, landscape design precedent and the ecological design process in the beginning design studios at Temple University's Ambler campus. As graphics is a skill that can be learned, so design is a process that can be learned and improved with practice. An appreciation of and response to the site's inherent opportunities and constraints is emphasized, in this more scientific, ecological approach to landscape design (Fig. 6).

Landscape design is part of the tradition at Ambler, Pa. Design has been a component of the landscape horticulture program since the Pennsylvania School of Horticulture for Women was founded in 1911. Louise BushBrown who was director of the program from 1924 to 1952 wrote America's Garden Book (1939)with her husband, James, who was a landscape architect. This has been a classical reference on garden design since it was first published. Our graduates include a number of nationally recognized landscape designers. Horticulture students learn the language and process of design. They can be effective communicators and participants in the multi-disciplinary teams that now typically address issues associated with the design, construction, maintenance and stewardship of the land. The symbiotic academic structure between horticulture and landscape architecture and further informal association with the architecture and environmental studies disciplines broad- ens our students education. It also provides a foundation for future professional collaborations.

\section{Literature cited}

American Nursery and Landscape Association. 2000. Industry statistics. 7 July 2000. <http://www.anla.org/industry/ index.htm>

Bush-Brown, L. and J. Bush-Brown. 1939. America's garden book. Charles Scribners, New York.

Lynch, K. 1960. The image of the city. M.I.T. Press, Cambridge, Mass.

Marcus, C.C. 1978. Remembrance oflandscapes past. Landscape J. 22:3.

Motloch, J.L. 1991. Introduction to landscape design. Van Nostrand Reinhold, New York.

Wong, W. 1988. Principles of two dimensional design. Van Nostrand Reinhold, New York. 